\title{
APPLICATION OF HIGH-PURITY ZEOLITE A SYNTHESIZED FROM DIFFERENT COAL COMBUSTION BY-PRODUCTS IN CARBON DIOXIDE CAPTURE
}

\author{
JULIANA IZIDORO ${ }^{1}$, DAVI CASTANHO ${ }^{1}$, CARLOS ROSSATI ${ }^{1}$, DENISE FUNGARO ${ }^{1}$, SABINE GUILHEN ${ }^{1}$, \\ THIAGO NOGUEIRA ${ }^{2,3}$ \& MARIA DE FÁTIMA ANDRADE ${ }^{3}$ \\ ${ }^{1}$ Centro de Química e Meio Ambiente, Instituto de Pesquisas Energéticas e Nucleares, Brazil \\ ${ }^{2}$ Departamento de Saúde Ambiental, Faculdade de Saúde Pública, Universidade de São Paulo, Brazil \\ ${ }^{3}$ Instituto de Astronomia, Geofísica e Ciências Atmosféricas, Universidade de São Paulo, Brazil
}

\begin{abstract}
High-purity zeolites A were synthesized from different coal combustion by-products (baghouse filter fly ash, cyclone filter ash, and bottom ash) and characterized in terms of morphology, chemical, and mineralogical composition. The products were tested for carbon dioxide capture by using a continuous $\mathrm{CO}_{2}$ flow system passing through a column packed with the adsorbent material, which was connected to an analyser that directly measures the concentration of $\mathrm{CO}_{2}$. The values of $\mathrm{CO}_{2}$ adsorption capacities calculated for the unmodified Na-A zeolites (ZABF, ZACF, and ZABA) were 556.48, 494.29 and $654.82 \mathrm{mg} \mathrm{g}^{-1}$, respectively. These values were higher than those achieved by the calcium-modified zeolite samples. ZABA adsorbent presented the best performance in $\mathrm{CO}_{2}$ capture when compared to the other adsorbent material and achieved an adsorption capacity $32 \%$ higher than a $4 \mathrm{~A}$ commercial zeolite. In the adsorption cycles study, the percentage of $\mathrm{CO}_{2}$ desorption by ZABA at the second and third cycles reached $93 \%$, showing that zeolite A can be regenerated by heating at $150{ }^{\circ} \mathrm{C}$. The use of coal ashes to obtain zeolites and the application of these products for the $\mathrm{CO}_{2}$ adsorption can be an important strategy to mitigate both the problem of waste management and the greenhouse gases emission in coal-fired power plants.
\end{abstract}

Keywords: carbon dioxide capture, coal combustion by-products, zeolite A.

\section{INTRODUCTION}

Climate change has been intensely questioned by scientists from different areas, society, and government around the world, due to the catastrophic consequences that the increase of the average global temperature can cause in the planet's ecosystem. According to the Intergovernmental Panel on Climate Change (IPCC), the average surface temperature of the earth between 1901 and 2012 is much higher than pre-industrial levels, indicating that human action may have been responsible for this temperature increase [1].

In this context, the burning of fossil fuels for energy generation, especially coal and oil, is pointed out as one of the main responsible sources for a large part of the carbon dioxide $\left(\mathrm{CO}_{2}\right)$ emitted in the atmosphere. Findings from several researches have shown a high correlation between the increase in $\mathrm{CO}_{2}$ atmospheric concentration and the increase of the earth surface temperature [1]. In addition to generating a large amount of $\mathrm{CO}_{2}$, coal-fired power plants also produce some solid wastes, known as coal combustion products (CCBs). These residues may have different physical and chemical characteristics, besides grain size, and those characteristics depend on the type of coal burning at the power plant, boiler operating temperature, type of particulate material retention system, etc. [2].

Among the many uses of CCBs, the synthesis of zeolites is considered an advanced strategy, since this material is a value-added product and has many applications $[3,4]$. The adsorption of $\mathrm{CO}_{2}$ by using zeolites is highlighted because it could eliminate both the problem of the accumulation of CCBs in sedimentation dams and the emission of $\mathrm{CO}_{2}$ by thermal power station. 
The application of zeolites for $\mathrm{CO}_{2}$ capture can be classified as a post-combustion technique, which means that $\mathrm{CO}_{2}$ removal is carried out after the coal [56]. The post-combustion technique can use either adsorbent material or porous solid to remove $\mathrm{CO}_{2}$ from the exhaust gaseous mixture and has the advantages of reducing emissions in a short term and also be implanted in already existing thermoelectric power plants. In addition to the zeolites, several materials with suitable properties for $\mathrm{CO}_{2}$ removal have been studied, such as carbonbased materials (activated carbon and graphene), mesoporous silica, modified organometals, amine-based materials, and lithium or calcium-based materials [7]. However, the use of highpurity zeolites in $\mathrm{CO}_{2}$ removal is widely studied because that material is synthesized from low-cost solid wastes, as coal ashes.

The efficiency of a $\mathrm{CO}_{2}$ separation process by adsorption depends on some properties of zeolites, such as high adsorption capacity, $\mathrm{CO}_{2}$ selectivity relating to other gases (e.g., SOx and NOx) and stability when exposed to humidity and gas flow temperature [8].

Different types of zeolites can be synthesized from coal combustion by-products. Zeolites type $\mathrm{A}$ and $\mathrm{X}$ present high $\mathrm{CO}_{2}$ adsorption capacity when compared to other types due to their textural properties and pore size [7,9-12]. Zeolites type A require shorter crystallization time when compared to type $\mathrm{X}$ zeolites, and therefore may present lower costs for their production $[2,13,14]$. Also, the mixture of $\mathrm{Na}-\mathrm{A}$ and $\mathrm{Na}-\mathrm{X}$ zeolites or only $\mathrm{Na}-\mathrm{A}$ zeolite presented better performance in $\mathrm{CO}_{2}$ adsorption in $\mathrm{N}_{2}$ atmosphere when compared to $\mathrm{X}$ zeolite, because of the higher selectivity for $\mathrm{CO}_{2}$ concerning $\mathrm{N}_{2}$ [12].

High-purity zeolite has many hydroxyl groups $(-\mathrm{OH})$ on its surface, which come from its tetrahedral structure and can act as a Lewis base. These hydroxyl groups bind to $\mathrm{CO}_{2}$, which acts as Lewis acid (Fig. 1) [15].

Acid-base interaction occurs due to the basicity of the zeolite surface, but since the surface is not entirely homogeneous, it may also presents heterogeneity in its basicity [15]. The cation exchange of the exchangeable cations in zeolites with alkaline or alkaline earth metals such as calcium may lead to an increase of the zeolite basicity and, therefore, can increase the adsorptive capacity of acidic gases such as $\mathrm{CO}_{2}[16]$.

Thus, this study aims to synthesize high-purity type A zeolites by using different coal combustion by-products and to apply them in the $\mathrm{CO}_{2}$ capture. A comparison among the performance of zeolite $\mathrm{A}$ in $\mathrm{CO}_{2}$ removal and both the calcium-modified zeolites and commercial 4A zeolite is also shown.
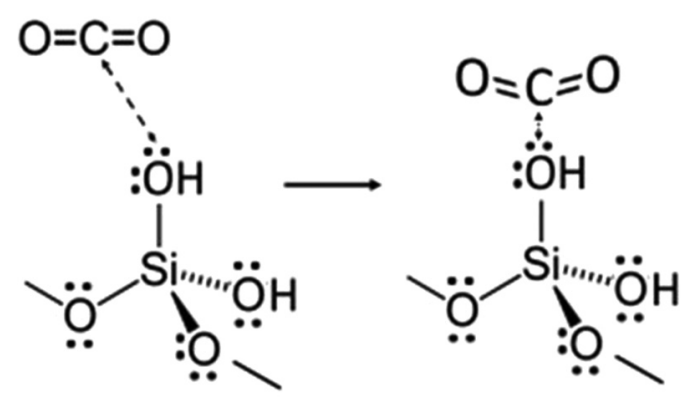

Figure 1: Mechanism of $\mathrm{CO}_{2}$ adsorption in high-purity zeolites. (source: Beltrao-Nunes et al., 2018). 


\section{MATERIALS AND METHODS}

\subsection{CCB samples}

Three different types of coal combustion by-products (CCBs), bottom ash, cyclone filter fly ash and baghouse filter fly ash were collected from Figueira Thermal Power Plant (FTPP), located in Paraná State (Brazil), in July 2015 and stored in plastic containers under environmental conditions.

\subsection{Synthesis of zeolite A with and without modification}

Na-A unmodified zeolites were synthesized from each CCB. Each ash sample was mixed with $\mathrm{NaOH}$ using a 1:1.2 mass ratio and grinded until a homogeneous mixture. The mixture was heated at $550{ }^{\circ} \mathrm{C}$ for $1 \mathrm{~h}$, cooled at room temperature and grinded. Sodium aluminate was added to the grinded mixture to control the $\mathrm{SiO}_{2} / \mathrm{Al}_{3} \mathrm{O}_{2}$ molar ratio and mixed with $100 \mathrm{~mL}$ of water. Each sample was then stirred at room temperature for $2 \mathrm{~h}$ at $150 \mathrm{rpm}$ and heated to $100^{\circ} \mathrm{C}$ in an oven for $3 \mathrm{~h}$. After cooling at room temperature, the suspension was filtered, and the solid was repeatedly washed with $1 \mathrm{~L}$ of deionized water and dried at $105^{\circ} \mathrm{C}$ overnight $[2,17]$. The products obtained were labelled as ZABF, ZACF and ZABA based on the CCBs sources (zeolite A from baghouse filter, zeolite A from cyclone filter and zeolite A from bottom ash, respectively).

Calcium-modified zeolites were obtained by ion exchange, and $3 \mathrm{~g}$ of each synthesized Na-A zeolite was added to $300 \mathrm{~mL}$ of $1 \mathrm{~mol} \mathrm{~L}^{-1}$ sodium acetate solution $\left(\mathrm{CH}_{3} \mathrm{COONa} .3 \mathrm{H}_{2} \mathrm{O}\right)$. The suspension was stirred at $25^{\circ} \mathrm{C}$ for $24 \mathrm{~h}$ at $120 \mathrm{rpm}$. Then, each sample was filtered, and the solid washed with $1 \mathrm{~L}$ of deionized water and dried in an oven at $80^{\circ} \mathrm{C}$. The dried samples were weighed and shaken at $25^{\circ} \mathrm{C}$ for $24 \mathrm{~h}$ at $120 \mathrm{rpm}$ with $100 \mathrm{~mL}$ of $1 \mathrm{~mol} \mathrm{~L}^{-1}$ calcium acetate solution $\left(\left(\mathrm{CH}_{3} \mathrm{COO}\right)_{2} \mathrm{Ca}\right)[16]$. The Ca-modified products were labelled as MZABF, MZACF and MZABA based on the CCB sources (for example, MZABF is modified zeolite A from baghouse filter).

\subsection{Characterization of zeolite A with and without modification}

Both unmodified and calcium-modified zeolite samples were characterized in terms of chemical composition by X-ray fluorescence (Bruker - S8 Tiger).

The mineralogical composition of the samples was determined by X-ray diffraction (Rigaku - Miniflex II) using $\mathrm{Cu} \mathrm{K} \alpha$ radiation at $30 \mathrm{kV}$ and $15 \mathrm{~mA}$. The scan rate was $0.05 \%$ and ranged from 5 to $55^{\circ}(2 \theta)$. Phase identification was made by searching the ICDD powder diffraction file database, with the help of Search-Match computer program. Each sample was covered with a thin layer of gold and examined using a scanning electron microscope to verify their morphology (HITACHI - TM300).

In cation exchange capacity (CEC) measurements, $1 \mathrm{~g}$ of each unmodified sample was saturated with $100 \mathrm{~mL}$ of sodium acetate solution $\left(1 \mathrm{~mol} \mathrm{~L}^{-1}\right)$, washed with $1 \mathrm{~L}$ of distilled water and then mixed with $100 \mathrm{~mL}$ of ammonium acetate solution $\left(1 \mathrm{~mol} \mathrm{~L}^{-1}\right)$. The sodium ion concentration of the remaining solution was determined by inductively coupled plasma optical emission (ICP-OES - Spectro - Arcos). 
2.4 Carbon dioxide adsorption studies

The efficiency in $\mathrm{CO}_{2}$ adsorption using the zeolites with and without modification was carried out in a continuous $\mathrm{CO}_{2}$ flow system with a known concentration (standard $\mathrm{CO}_{2} / \mathrm{N}_{2} 0.1 \%$ Air Products - USA) passing through a column packed with the adsorbent material and connected to an analyser that did measurements of $\mathrm{CO}_{2}$ concentration directly (PICARRO analyser - G2301).

The column used in this study was assembled with a colourless PVC pipe of $6.5 \mathrm{~cm}$ in length and $3 \mathrm{~cm}$ in diameter, attached to the ends with carbon steel connections with zinc surface finish, generally used in industrial gas pipes to prevent leaks. A mass of $3 \mathrm{~g}$ of each adsorbent material was compacted into the columns with $2.5 \mathrm{~cm}$ of ultrapure glass wool at each end. Initially, the $\mathrm{CO}_{2}$ flow was adjusted in $900 \mathrm{~mL} \mathrm{~min}^{-1}$, which is the flow in which the equipment operates to obtain reliable data and also to establish a standardized methodology for $\mathrm{CO}_{2}$ concentration measurements and subsequent adsorption capacities comparison among the different adsorbent materials. The $\mathrm{CO}_{2}$ adsorption system, as well as the column used in the tests, is shown in Fig. 2.

The equipment measured the initial $\mathrm{CO}_{2}$ concentration after a purge with ultrapure nitrogen (Air Products). The columns were assembled for each zeolite and purged with $\mathrm{N}_{2}$ for 3 min, in order to remove interfering gases and impurities from the column filling, followed by the passage of $\mathrm{CO}_{2}$ flow during $20 \mathrm{~min}$. The acquired data in the equipment were analysed for the determination of the saturation time of each sample. The adsorption capacity of each adsorbent per mass unit (q) was calculated by eqn (1) [16].

$$
q=\frac{Q \times C_{0} \times 24.45}{W} \int_{0}^{t_{s}}\left(1-\frac{C}{C_{0}}\right) \mathrm{dt} .
$$

where $q$ is the adsorbed amount $\left(\mathrm{mmol} \mathrm{g}^{-1}\right), Q$ is the gas flow $\left(\mathrm{L} \mathrm{min}^{-1}\right), W$ is the weight of adsorbent used (g), $C_{0}$ and $C$ are the initial and final $\mathrm{CO}_{2}$ concentrations, respectively (ppm), $t_{s}$ is the saturation time and 24.45 is the factor which represents the molar volume in operating conditions ( $1 \mathrm{~atm}$ and $25^{\circ} \mathrm{C}$ ).

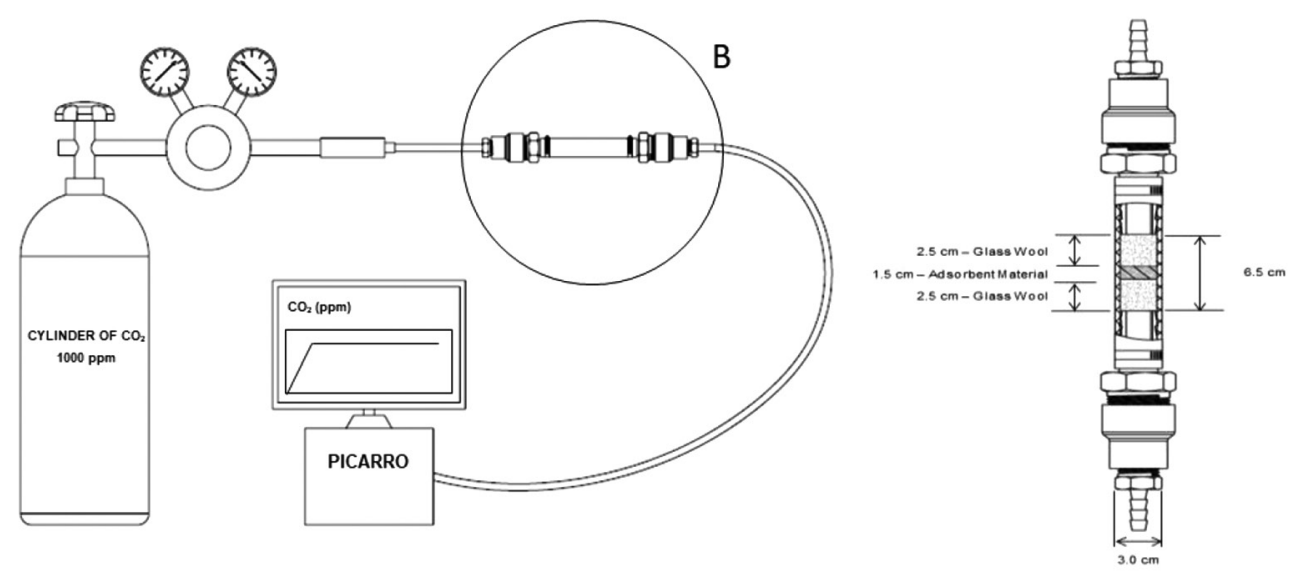

Figure 2: (a) Scheme of the $\mathrm{CO}_{2}$ adsorption system; (b) Column containing adsorbent material used in the $\mathrm{CO}_{2}$ adsorption system (detail B). 


\subsection{Carbon dioxide desorption studies}

The adsorbent material that presented the best $\mathrm{CO}_{2}$ removal performance when compared to others (ZABA) was chosen for the adsorption/desorption cycle tests in order to determine how many times that material could be reused. The column used for the $\mathrm{CO}_{2}$ desorption studies was assembled with a synthetic rubber pipe with the same dimensions of the column used for the adsorption tests (described in item 2.4), but with the capacity to withstand higher temperatures. After each adsorption step with the ZABA sample, the desorption step was initiated by heating the column containing the $\mathrm{CO}_{2}$-saturated adsorbent at $150^{\circ} \mathrm{C}$ (temperature at which the $\mathrm{CO}_{2}$ is desorbed from zeolite $\mathrm{A}$ as determined by thermogravimetry in previous studies) during 30 min with a $\mathrm{N}_{2}$ gas flow. Posteriorly, heating was withdrawn from the system, and the $\mathrm{N}_{2}$ flow was maintained until the sample reached room temperature. After this step, the adsorption/desorption cycles were repeated. All $\mathrm{CO}_{2}$ concentration data were acquired by a PICARRO analyser. The amount of desorbed $\mathrm{CO}_{2}$ was calculated by eqn (2) (Adapted from [16]).

$$
q=\frac{Q \times 24.45 \times 44 \times 10^{-6}}{W} \int_{0}^{t_{f}}(C) \mathrm{dt} .
$$

where $q$ is the $\mathrm{CO}_{2}$ desorbed amount $\left(\mathrm{mg} \mathrm{CO}_{2} \mathrm{~g}^{-1}\right), Q$ is the gas flow $\left(\mathrm{mL} \mathrm{s}^{-1}\right), C$ is the $\mathrm{CO}_{2}$ concentration in the column output (ppm), $W$ is the weight of adsorbent used $(\mathrm{g}), t_{s}$ is the analysis time (s), $\int_{0}^{t_{f}}(C) \mathrm{dt}$ represents the area below the graph plotted from $t_{s}$ versus $C, 24.45$ is the factor which represents the molar volume in operating conditions $\left(1 \mathrm{~atm}\right.$ and $\left.25^{\circ} \mathrm{C}\right)$ and $44 \mathrm{~g} \mathrm{~mol}^{-1}$ is the $\mathrm{CO}_{2}$ molar mass.

\section{RESULTS AND DISCUSSION}

\subsection{Characteristics of synthesized zeolites}

\subsubsection{Unmodified zeolites}

The chemical compositions of three zeolites samples synthesized from the different CCBs are given in Table 1 (by \% weight). High-purity zeolites showed similar quantities of the major elements usually encountered in this type of products (silicon, aluminium, sodium and iron), independent of the sample. All other constituents were below $3 \%$ for all samples.

The content of silicon and aluminium, which are the structural elements for zeolites, represented together at least $50 \%$ for the three products, while sodium content, which is the exchangeable cation of the zeolitic structures, varied between 15.5 and $16.4 \%$. The $\mathrm{SiO}_{2} /$ $\mathrm{Al}_{2} \mathrm{O}_{3}$ ratio was 1.24 for both ZABA and ZACF and 1.22 for ZABF. According to Querol et al. [9], those ratios can be related to the zeolite $\mathrm{CEC}$. In addition, the $\mathrm{SiO}_{2} / \mathrm{Al}_{2} \mathrm{O}_{3}$ ratios for the zeolites are lower than the values of raw fly ashes, determined in previous studies [18], indicating that the zeolite synthesis treatment contributed to the increase in the CEC of these materials, because the lower $\mathrm{SiO}_{2} / \mathrm{Al}_{2} \mathrm{O}_{3}$ ratio, the higher CEC of the zeolites [9].

Synthesized zeolites also presented a loss of ignition (LOI) of 20.9, 17.6 and $12.6 \%$ for ZABA, ZACF and ZABF samples, respectively. LOI values can indicate the presence of organic material or lighter compounds, which are not sensitive to the X-ray fluorescence technique. ZABA sample presented the highest LOI value when compared to the other CCBs 
Table 1: Composition (wt $\%$ ) of high-purity A zeolites.

\begin{tabular}{|c|c|c|c|}
\hline Components & ZABA & ZACF & $\mathrm{ZABF}$ \\
\hline $\mathrm{SiO}_{2}$ & 29.6 & 30.1 & 32.8 \\
\hline $\mathrm{Al}_{2} \mathrm{O}_{3}$ & 23.8 & 24.2 & 26.9 \\
\hline $\mathrm{Na}_{2} \mathrm{O}$ & 15.5 & 16.0 & 16.4 \\
\hline $\mathrm{Fe}_{2} \mathrm{O}_{3}$ & 6.15 & 7.75 & 6.89 \\
\hline $\mathrm{CaO}$ & 1.82 & 2.34 & 1.53 \\
\hline $\mathrm{K}_{2} \mathrm{O}$ & 0.610 & 0.575 & 0.712 \\
\hline $\mathrm{SO}_{3}$ & 0.191 & 0.115 & 0.106 \\
\hline $\mathrm{TiO}_{2}$ & 0.554 & 0.531 & 0.807 \\
\hline $\mathrm{MgO}$ & 0.577 & 0.481 & 0.636 \\
\hline $\mathrm{ZnO}$ & 0.062 & 0.096 & 0.319 \\
\hline $\mathrm{MnO}$ & 0.051 & 0.074 & 0.042 \\
\hline $\mathrm{Cr}_{2} \mathrm{O}_{3}$ & 0.009 & 0.011 & 0.016 \\
\hline $\mathrm{PbO}$ & 0.005 & 0.010 & 0.031 \\
\hline Others & $<0.07$ & $<0.07$ & $<0.07$ \\
\hline LOI & 20.9 & 17.6 & 12.6 \\
\hline
\end{tabular}

because it was synthesized from the CCB which was exposed a shorter time to the flue gases during the burning of the coal at the power plant (bottom ash), and, therefore, presented a high content of unburnt carbon [19].

The CEC values of zeolites are shown in Table 2. The decreasing CEC values of samples were as follows: $\mathrm{ZABF}>\mathrm{ZABA}>\mathrm{ZACF}$. All CEC values are similar to previous results in other studies [2], [23,24]. The highest CEC value for the ZABF sample was expected since this product also presented the lowest $\mathrm{SiO}_{2} / \mathrm{Al}_{2} \mathrm{O}_{3}$ ratio as explained previously.

Figure 3 shows X-ray diffraction patterns of unmodified zeolites. All products are very similar and are composed mainly of zeolite A phase and some trace amounts of quartz and

Table 2: Cation exchange capacity of zeolite A.

\begin{tabular}{lc}
\hline Sample & CEC $\left(\mathrm{meq} \mathrm{g}^{-1}\right)$ \\
\hline ZABA & 3.2 \\
ZACF & 3.0 \\
ZABF & 3.4 \\
\hline
\end{tabular}


(a)
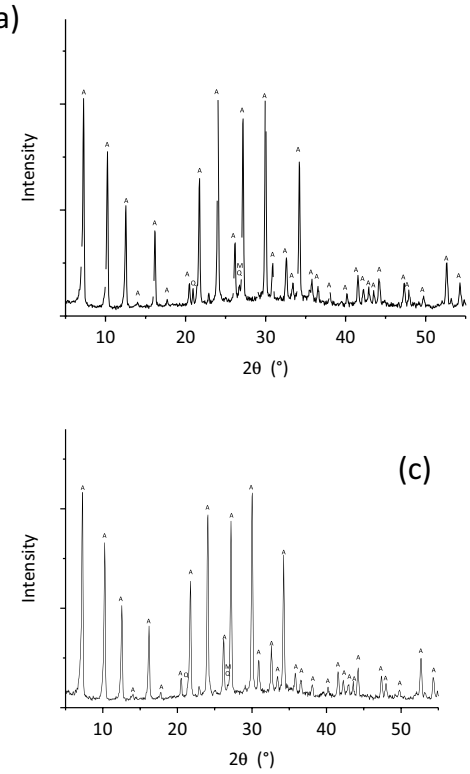

c) (b)

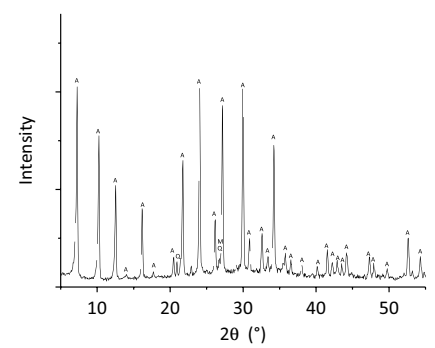

Figure 3: XRD Patterns of (a) ZABA; (b) ZACF; (c) ZABF (A = Zeolite A, Q = quartz and $\mathrm{M}=$ mullite).

mullite. The zeolite $X$-ray diffraction patterns are very similar to previous observations in other studies which synthesized high-purity A zeolites by using different CCB sources [2,20-22]. Figure 4 shows the scanning electron micrographs (SEMs) of the three zeolites. Type A zeolites typically have a cubic structure $[2,21,22]$, and its presence in the samples can be verified that zeolite $\mathrm{A}$ is the main phase, as previously identified by X-ray diffraction.

The X-ray diffraction patterns showing zeolite $\mathrm{A}$ as the main phase, the cubic structures shown in SEM micrographs (Fig. 7) and also the CEC values indicate that zeolites which were synthesized by the method described in this study, by using different raw materials, can be considered as high-purity products.

\subsubsection{Calcium-modified zeolites}

The chemical compositions of three calcium-modified zeolites samples are given in Table 3 (by $\%$ weight). The results are very similar to unmodified zeolites (Table 1), where Si and Al
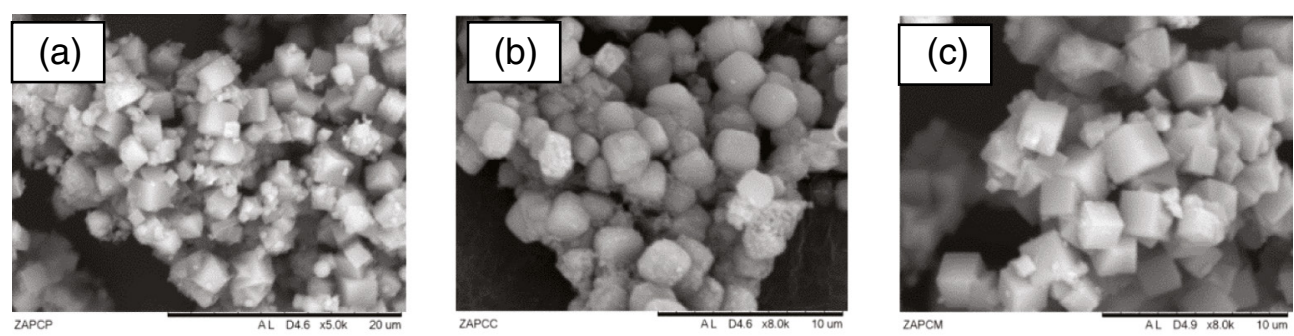

Figure 4: SEM micrographs of (a) ZABA, (b) ZACF, (c) ZABF. 
Table 3: Composition (wt\%) of Ca-modified zeolites.

\begin{tabular}{lccc}
\hline Components & MZABA & MZACF & MZABF \\
\hline $\mathrm{SiO}_{2}$ & 26.8 & 21.1 & 23.5 \\
$\mathrm{Al}_{2} \mathrm{O}_{3}$ & 19.3 & 15.9 & 18.1 \\
$\mathrm{CaO}$ & 10.7 & 16.5 & 16.3 \\
$\mathrm{Fe}_{2} \mathrm{O}_{3}$ & 7.12 & 9.23 & 6.45 \\
$\mathrm{Na}_{2} \mathrm{O}$ & 4.88 & 2.42 & 2.85 \\
$\mathrm{TiO}_{2}$ & 0.64 & 0.57 & 0.76 \\
$\mathrm{MgO}_{\mathrm{K}} \mathrm{O}$ & 0.56 & 0.40 & 0.45 \\
$\mathrm{SO}_{3}$ & 0.44 & 0.17 & 0.17 \\
$\mathrm{BaO}$ & 0.28 & 0.19 & 0.16 \\
$\mathrm{ZnO}_{\mathrm{MnO}}$ & 0.1 & 0.08 & 0.12 \\
$\mathrm{ZrO}_{2}$ & 0.06 & 0.09 & 0.23 \\
$\mathrm{CuO}$ & 0.05 & 0.05 & 0.04 \\
$\mathrm{SrO}$ & 0.05 & 0.05 & 0.07 \\
$\mathrm{Cr}$ & 0.04 & $<0.01$ & $<0.01$ \\
$\mathrm{Others}$ & 0.03 & 0.04 & 0.05 \\
$\mathrm{LOI}$ & 0.02 & 0.02 & 0.02 \\
\hline
\end{tabular}

were the main elements. A significant amount of $\mathrm{Ca}$ was incorporated in the final products due to modification by ion exchange. The content of $\mathrm{Fe}$ and $\mathrm{Na}$ ranging between $2.42 \%$ and 9.23\% was also found in the samples. Quantities below $1 \%$ of all other elements are also observed. The LOI values for the Ca-modified zeolites were higher than those presented for unmodified zeolites (Table 1) and ranged from 28.9 (MZABA) to $32.9 \%$ (MZACF). That difference may have occurred because Ca zeolites are more hygroscopic than the Na zeolites, and therefore can adsorb water from the atmosphere.

Figure 5 shows the diffractograms obtained for MZABA, MZACF and MZABF, respectively. The three samples are composed mainly of zeolite A phase and some trace amounts of quartz and mullite, as the unmodified zeolites, indicating that calcium modification methodology did not influence the crystalline phases formed. The SEM photos of the Ca-modified zeolites are shown in Fig. 6 . The three products are formed by cubes, similar to the unmodified zeolite micrographs (Fig. 4).

3.2 $\mathrm{CO}_{2}$ adsorption tests with Na-A zeolites

The $\mathrm{CO}_{2}$ removal by Na-A zeolites was evaluated by comparing the adsorption performance of both these products and the commercial 4A zeolite. The results are shown in Fig. 7. The $\mathrm{CO}_{2}$ adsorption breakdown curves show a high affinity between adsorbate and adsorbents. 

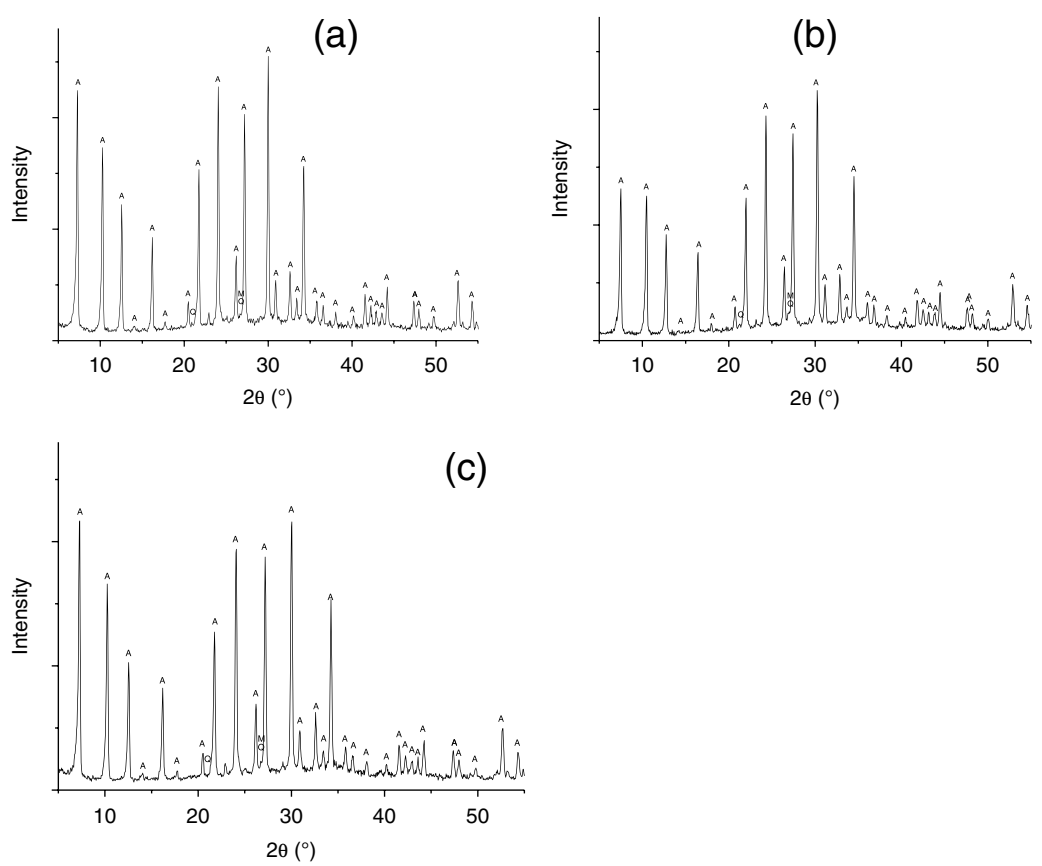

Figure 5: XRD Patterns of (a) MZABA, (b) MZACF, (c) MZABF Ca-modified zeolites ( $\mathrm{A}=$ zeolite $\mathrm{A}, \mathrm{Q}=$ quartz and $\mathrm{M}=$ mullite).
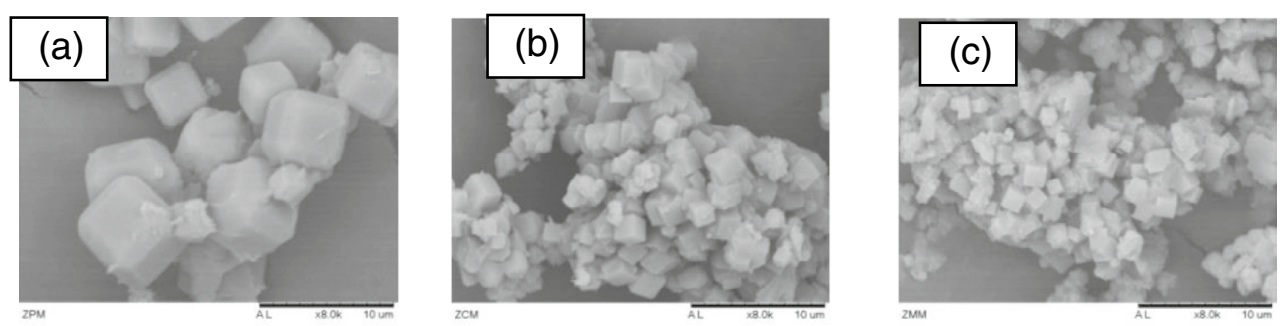

Figure 6: SEM micrographs of Ca-modified zeolites: (a) MZABA, (b) MZACF, (c) MZABF.

All curves were very similar for the three products. The saturation time and the $\mathrm{CO}_{2}$ adsorbed amount calculated for each sample are shown in Table 4.

According to Table 4, the saturation time was around 1,200 s for all zeolites. The adsorption capacities varied from $492.29 \mathrm{mg} \mathrm{g}^{-1}$ (ZACF) to $654.82 \mathrm{mg} \mathrm{g}^{-1}$ (ZABA). Na-A zeolites can be considered as excellent $\mathrm{CO}_{2}$ adsorbents since they presented adsorption capacities values much higher than $176 \mathrm{mg} \mathrm{g}^{-1}$ [26]. According to the adsorption capacities showed in Table 4, the sample synthesized from bottom ash (ZABA) presented better performance in $\mathrm{CO}_{2}$ removal when compared to the other samples. The high affinity of ZABA for $\mathrm{CO}_{2}$ can be 


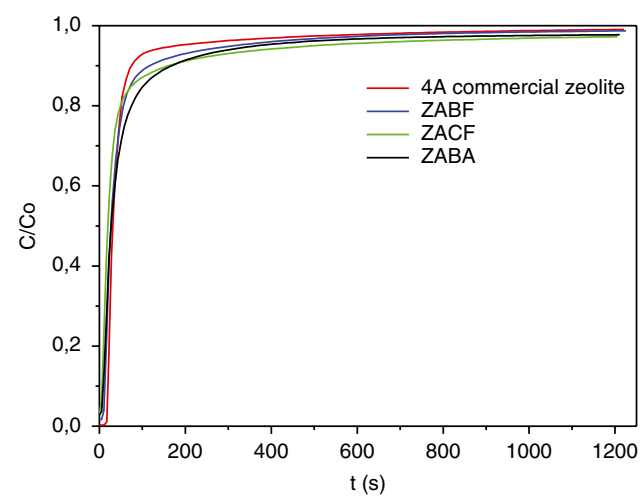

Figure 7: $\mathrm{CO}_{2}$ adsorption breakdown curve onto zeolites 4A Commercial, ZABF, ZACF and ZABA.

Table 4: Saturation time and $\mathrm{CO}_{2}$ adsorption capacity for Na-A zeolites.

\begin{tabular}{lccccc}
\hline Sample & $* t_{\text {sat }}(\mathrm{s})$ & $\begin{array}{c}C_{0} \\
(\mathrm{ppm})\end{array}$ & $Q\left(\mathrm{~mL} \cdot \mathrm{min}^{-1}\right)$ & $\int_{0}^{t}\left(1-\frac{C}{C_{0}}\right) d \mathrm{t}$ & $\begin{array}{c}* * \mathrm{CO}_{2 \text { ads }} \\
(\mathrm{mg} / \mathrm{g} \text { sample })\end{array}$ \\
\hline 4A & 1,221 & $1,387.68$ & 900 & 66.64 & 497.41 \\
ZABF & 1,225 & $1,387.68$ & 900 & 74.55 & 556.48 \\
ZACF & 1,206 & $1,012.13$ & 930 & 87.51 & 492.29 \\
ZABA & 1,211 & $1,387.68$ & 900 & 87.73 & 654.82 \\
\hline
\end{tabular}

$* t_{\text {sat }}=$ saturation time; $* * \mathrm{CO}_{2 \text { ads }}=$ adsorbed $\mathrm{CO}_{2}$.

related to its high content of organic matter or unburned carbon, evidenced in its LOI value (20.9\%, Table 1 ). Those compounds may be acting as adsorbents for $\mathrm{CO}_{2}$, besides the formed zeolite A. It is important to note that the adsorption capacities of ZACF and ZABF zeolites were very similar to the value of $4 \mathrm{~A}$ commercial zeolite. On the other hand, ZABA sample achieved an adsorption capacity $32 \%$ higher than 4A zeolite.

3.3 $\mathrm{CO}_{2}$ adsorption studies with $\mathrm{Ca}-\mathrm{A}$ zeolites

The $\mathrm{CO}_{2}$ adsorption study by using the $\mathrm{Ca}$-A zeolites was performed in order to evaluate the $\mathrm{CO}_{2}$ removal capacity before and after the material modification. The breakdown curves and the calculated data for the modified zeolite samples (MZABF, MZACF, and MZABA) are shown in Fig. 8 and Table 5, respectively.

According to results, the saturation time was very similar to the values of unmodified samples (around 1,200-1,230 s for all zeolites). The adsorption capacities varied according to the zeolite type, although the variation was lower than those observed for unmodified materials. Ca-modified zeolites presented lower adsorption capacity when compared to unmodified zeolites because modified materials are more hygroscopic than the Na-zeolites, 


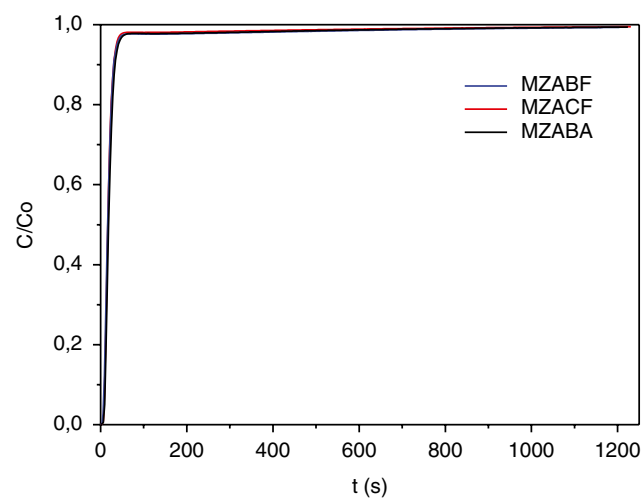

Figure 8: $\mathrm{CO}_{2}$ adsorption breakdown curve onto Ca-modified zeolites MZABF, MZACF and MZABA.

Table 5: Saturation time and $\mathrm{CO}_{2}$ adsorption capacities for Ca-A zeolites.

\begin{tabular}{lccccc}
\hline Sample & $* t_{\text {sat }}(\mathrm{s})$ & $C_{0}(\mathrm{ppm})$ & $Q^{\left(\mathrm{mL} \cdot \mathrm{min}^{-1}\right)}$ & $\int_{0}^{t}\left(1-\frac{C}{C_{0}}\right) d \mathrm{t}$ & $\begin{array}{c}{ }^{* *} \mathrm{CO}_{\text {2ads }} \\
(\mathrm{mg} / \mathrm{g} \text { sample })\end{array}$ \\
\hline MZABF & 1,204 & $1,012.27$ & 900 & 35.24 & 191.86 \\
MZACF & 1,230 & $1,012.27$ & 900 & 32.22 & 175.41 \\
MZABA & 1,224 & $1,012.27$ & 900 & 36.43 & 198.34 \\
\hline
\end{tabular}

$* t_{\text {sat }}=$ saturation time; $* * \mathrm{CO}_{2 \mathrm{ads}}=$ adsorbed $\mathrm{CO}_{2}$.

and therefore, the adsorbed water molecules can probably occupy the zeolite structure spaces available for $\mathrm{CO}_{2}$ removal. These results are in accordance with Lee \& Jo [16].

$3.4 \mathrm{CO}_{2}$ adsorption and desorption cycle study

The adsorption and desorption studies were performed in order to verify the amount of $\mathrm{CO}_{2}$ that desorbed from saturated zeolite sample, and also whether there is a total or partial regeneration of those kinds of material when subjected to high temperatures. ZABA sample was selected for the tests because it presented the best results in the adsorption studies when compared to other samples.

The adsorption and desorption curves of ZABA are shown in Fig. 9, where it is possible to verify that a behaviour change occurred after the first desorption step, similar to the curves obtained by Costa [25]. This behaviour can indicate that activation of the zeolite surface occurred undergoes the first heating (desorption step). The $\mathrm{CO}_{2}$ adsorption and desorption curves were used for the calculations presented in Table 6 .

According to Table 6, the result of the first adsorption step was similar to the test performed previously with the same sample (Table 4 ). The adsorption capacity reached by ZABA was $616.88 \mathrm{mgCO}_{2}$ per gram of zeolite. 


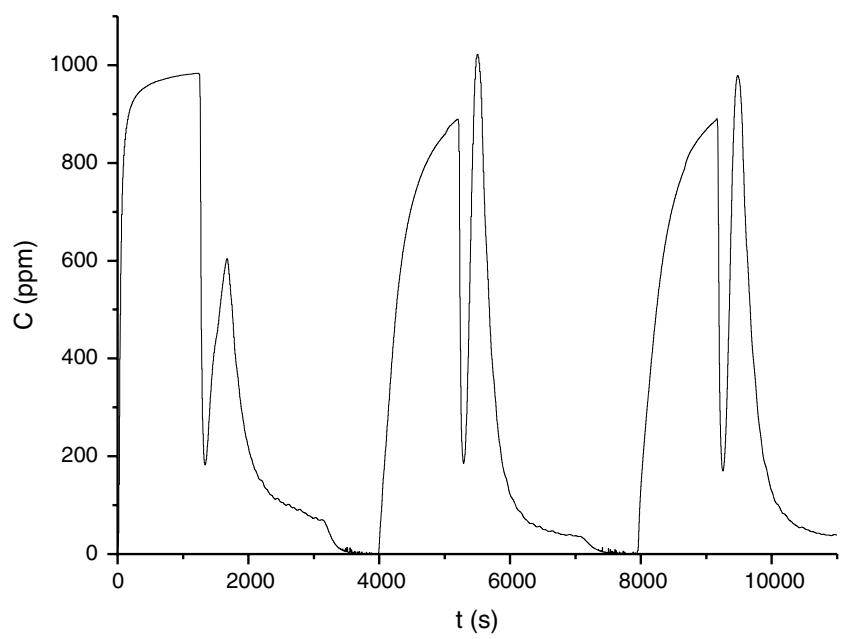

Figure 9: $\mathrm{CO}_{2}$ adsorption and desorption curves onto ZABA sample.

Table 6: Saturation time and $\mathrm{CO}_{2}$ adsorbed and desorbed amount onto ZABA sample during each cycle.

\begin{tabular}{|c|c|c|c|c|c|c|}
\hline Cycle & Phenomenon & $t(\mathrm{~s})$ & $\begin{array}{c}Q \\
\left(\mathrm{~mL} \min ^{-1}\right)\end{array}$ & $\int_{0}^{\mathrm{t}}\left(1-\frac{C}{C_{0}}\right) \mathrm{dt}$ & $\int_{0}^{\mathrm{t}}(C) \mathrm{dt}$ & $\begin{array}{c}\mathrm{CO}_{2} \\
\left(\mathrm{mg} \mathrm{g}^{-1}\right)\end{array}$ \\
\hline $1^{\circ}$ & Adsorption & 1,236 & 900 & 109.64 & - & 616.88 \\
\hline $1^{\mathrm{o}}$ & Desorption & 2,073 & 930 & - & 404,217 & $2,174.28$ \\
\hline $2^{\circ}$ & Adsorption & 1,222 & 900 & 431.39 & - & $2,427.19$ \\
\hline $2^{\circ}$ & Desorption & 2,011 & 930 & - & $422,384.58$ & $2,272.01$ \\
\hline $3^{\circ}$ & Adsorption & 1,224 & 900 & 440.82 & - & $2,480.25$ \\
\hline $3^{\circ}$ & Desorption & 1,743 & 930 & - & $425,713.02$ & 2,289.91 \\
\hline
\end{tabular}

It is also observed that the sample released a quantity of $\mathrm{CO}_{2}$ higher than the quantity adsorbed in the first cycle. This is believed to have happened because the released $\mathrm{CO}_{2}$ under high temperature can cause an activation on the zeolite surface, as previously mentioned. Posteriorly, ZABA showed a capacity to capture 2,427.19 and 2,480.25 $\mathrm{mgCO}_{2}$ per gram of zeolite at the second and third adsorption steps, respectively, showing that there were more active sites capable of adsorbing $\mathrm{CO}_{2}$ after first desorption step. The percentage of $\mathrm{CO}_{2}$ desorption by ZABA at the second and third cycles reached $93 \%$, showing that zeolite A can be regenerated by heating at $150^{\circ} \mathrm{C}$.

\section{CONCLUSION}

High-purity Na-A zeolites were obtained from different CCBs, and their structures were confirmed by X-ray diffraction and scanning electron microscopy techniques. The $\mathrm{CO}_{2}$ adsorption capacities were 556.48, 494.29 and $654.82 \mathrm{mg} \mathrm{g}^{-1}$ for unmodified zeolites 
ZABF, ZACF, and ZABA, respectively. The saturation time, around 1,200 s, was similar for Ca-modified and unmodified zeolites. The best performing sample was the type A zeolite synthesized from bottom ash without modification (ZABA), which showed a $32 \%$ higher adsorption capacity than the commercial zeolite. ZABA was tested for adsorption and desorption cycles in order to determine the regeneration efficiency. The percentage of $\mathrm{CO}_{2}$ desorption by ZABA at the second and third cycles reached $93 \%$, showing that zeolite A can be regenerated by heating at $150^{\circ} \mathrm{C}$. It should be noted that bottom ashes do not find commercial application in Brazil and are usually disposed of in abandoned mines or transported to sedimentation ponds by hydraulic pumping. Therefore, the use of bottom ashes to obtain zeolites and the application of these products for the $\mathrm{CO}_{2}$ adsorption can be an important strategy to mitigate both the problem of waste management and the greenhouse gases emission in coal-fired power plants.

\section{REFERENCES}

[1] Intergovernamental Panel on Climate Change - IPCC - Global warming of $1.5^{\circ} \mathrm{C}$, Online, https://www.ipcc.ch/sr15/. Accessed on: 14 Jan. 2018.

[2] Izidoro, J. C., Fungaro, D. A., Abbott, J. E. \& Wang, S., Synthesis of zeolites X and A from fly ashes for cadmium and zinc removal from aqueous solutions in single and binary ion systems. Fuel. 103 (1), pp. 827-834, 2012.

[3] Ahmaruzzaman, M. A review on the utilization of fly ash. Prog. Energ. Combust. 36, pp. 327-363, 2010.

[4] Yao, Z. T., Ji, X. S., Sarker, P. K., Tang, J. H., Ge, L. Q., Xia, M. S. \& Xi, Y. Q., A comprehensive review on the applications of coal fly ash. Earth Sci Rev. 141, pp. 105-121, 2015.

[5] Herzog, H. J., What future for carbon capture and sequestration? Environ. Sci. Technol. 35, pp. 148-153, 2001.

[6] Yang, H., Xu, Z., Fan, M., Gupta, R., Slimane, R. B. \& Bland, A. E., Progress in carbon dioxide separation and capture: A review. J. Environ. Sci. 20, pp. 14-27, 2008.

[7] Samanta, A., Zhao, A., Shimizu, G. K. H., Sarkar, P. \& Gupta, R. Post-combustion $\mathrm{CO}_{2}$ capture using solid sorbents: A review. Ind. \& Eng. Chem. Res., 51, pp. 1438-1463, 2012.

[8] Song, C., Xu, X., Miller, B. G. \& Scaroni, A. W., Adsorption separation of carbon dioxide from flue gas of natural gas-fired boiler by a novel nanoporous "molecular basket" adsorbent. Fuel Proc. Technol. 86, pp. 1457-1472, 2005.

[9] Querol, X., Moreno, N., Umaña, J. C., Juan, R., Hernandez, S., Fernandez, P. C., Ayora, C., Janssen, M., Garcia, J. M. J., Linares, S. A. \& Cazorla, A. D., Application of zeolitic material synthesized from fly ash to the decontamination of waste water and flue gas. J. Chem. Technol. Biotechnol. 77, pp. 292-298, 2002.

[10] Majchrzak-Kuceba, I. \& Nowak, W., A thermogravimetric study of the adsorption of $\mathrm{CO}_{2}$ on zeolite synthesized from fl y ash. Thermochim. Acta. 437, pp. 67-74, 2005.

[11] Bonenfant, D., Kharoune, M., Niquette, P., Mimeault, M. \& Hausler, R., Advances in principal factors influencing carbon dioxide adsorption on zeolites. Sci. Technol. Adv. Mater. 9, pp. 1-7, 2008.

[12] Li, G. K., Singh, R., Xiao, P. \& Zhai, Y., Zeolite synthesis from waste fly ash and its application in $\mathrm{CO}_{2}$ capture from flue gas streams. Adsorption. 17 (5), pp. 795-800, 2011.

[13] Ojha, K., Pradhan, N. M. C. \& Samanta, A. M. Zeolite from fly ash: synthesis and characterization. Bull. Mater. Sci. 27, pp. 555-564, 2004. 
[14] El-Naggar, M. R., El-Kamash, A. M., El-Dessouky, M. I. \& Ghonaim, A. K., Two-step method for preparation of NaA-X zeolite blend from fly ash for removal of cesium ions. J. Hazard. Mater. 154, pp. 963-972, 2008.

[15] Beltrao-Nunes, A. P., Sennour, R., Arus, V. A., Anoma, S., Pires, M., Bouazizi, N. \& Roy, R., Azzouz, A., $\mathrm{CO}_{2}$ capture by coal ash-deriving zeolites- roles of the intrinsic basicity and hydrophilic character. Journal of Alloys and Compounds. 778, pp. 866-877, 2018.

[16] Lee, K-M. \& Jo, Y-M., Synthesis of zeolite from waste fly ash for adsorption of $\mathrm{CO}_{2} . J$ Mater Cycles Waste Manag. 12, pp. 212-219, 2010.

[17] Rossatti, C., Castanho, D., Izidoro, J. C. \& Fungaro, D. A., Otimização da síntese de zeólita Na-a de elevada purezaobtida a partir de cinzas volantes de carvão. V Congresso Brasileiro de Carvão Mineral- VCBCM, p. 006, Santa Catarina, 2017.

[18] Izidoro, J. C., Miranda, C., Ghilhen, S. N. \& Fungaro, D. A., Chemical, mineralogical and environmental characterization of combustion by-products generated from mineral coal used for electricity production. Proceedings of the 13th International Conference on Materials Chemistry - MC13, p. 046, 2017.

[19] Izidoro, J. C., Miranda, C. S., Guilhen, S. N., Fungaro, D. A. \& Wang, S., Treatment of coal ash landfill leachate using zeolitic materials from coal combustion by-products. Adv Mat Tech Env. 2 (1), pp. 177-186, 2018.

[20] Chang, H-L. \& Shih, W-H., A general method for the conversion of fly ash into zeolites as ion exchangers for cesium. Ind Eng Chem Res. 37, pp. 71-78, 1998.

[21] Wang, C-F., Li, J-S., Wang, L-J. \& Sun, X-Y., Influence of $\mathrm{NaOH}$ concentrations on synthesis of pure-form zeolite A from fly ash using two-stage method. J Hazard Mater. 155, pp. 58-64, 2008.

[22] Tanaka, H. \& Fujii, A., Effect of stirring on the dissolution of coal fly ash and synthesis of pure-form Na-A and $-\mathrm{X}$ zeolites by two-step process. Adv Powder Technol. 20, pp. 473-479, 2009.

[23] Hollman, G., Steenbruggen, G. \& Jansen-Jurkovicova, M., A two-step process for the synthesis of zeolites from coal fly ash. Fuel. 78, pp. 1225-1230, 1999.

[24] Ye, Y., Zeng, X., Qian, W. \& Wang, M., Synthesis of pure zeolites from supersaturated silicon and aluminum alkali extracts from fused coal fly ash. Fuel. 87, pp. 880-886, 2008.

[25] Costa, B. M., Síntese de zeólitas a partir de cinzas de carvão para captura de dióxido de carbono. Pontifícia Universidade Católica do Rio Grande do Sul, Porto Alegre, pp. 91, 2016.

[26] Sayari, A., Belmabkhout, Y. \& Serna-Guerrero, R., Flue Gas Treatment via $\mathrm{CO}_{2}$ Adsorption. Chem. Eng. J. 171, pp. 760-774, 2011. 